\title{
Corrigendum to "Safety Impacts of Push-Button and Countdown Timer on Nonmotorized Traffic at Intersections"
}

\author{
Bei Zhou $\mathbb{D}^{1},{ }^{2}$ Arash $M$. Roshandeh $\mathbb{D}^{2},{ }^{2}$ and Shengrui Zhang $\mathbb{D}^{1}$ \\ ${ }^{1}$ School of Highway, Chang'an University, Xian 710064, China \\ ${ }^{2}$ School of Civil Engineering, Purdue University, West Lafayette, IN 47907, USA \\ Correspondence should be addressed to Bei Zhou; bzhou3@chd.edu.cn
}

Received 25 July 2018; Accepted 2 August 2018; Published 19 August 2018

Copyright (C) 2018 Bei Zhou et al. This is an open access article distributed under the Creative Commons Attribution License, which permits unrestricted use, distribution, and reproduction in any medium, provided the original work is properly cited.

In the article titled "Safety Impacts of Push-Button and Countdown Timer on Nonmotorized Traffic at Intersections" [1], the vehicle crash data the authors used was used without the authorization from the Transportation Engineering Laboratory (TE Lab) at Illinois Institute of Technology. Accordingly, an acknowledgment should be added:

The authors would like to thank Dr. Zongzhi Li, the faculty Director of Transportation Engineering Laboratory (TE Lab) at Illinois Institute of Technology, Chicago, USA, for collecting the crash data used in the article.

\section{References}

[1] B. Zhou, M. Roshandeh Arash, and S. Zhang, "Safety Impacts of Push-Button and Countdown Timer on Nonmotorized Traffic at Intersections," Mathematical Problems in Engineering, vol. 2014, Article ID 460109, 6 pages, 2014. 


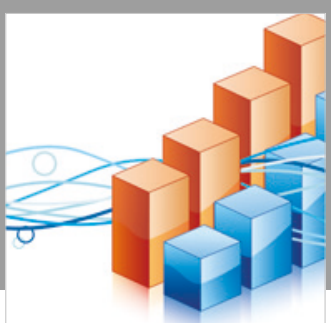

Advances in

Operations Research

\section{-n-m}
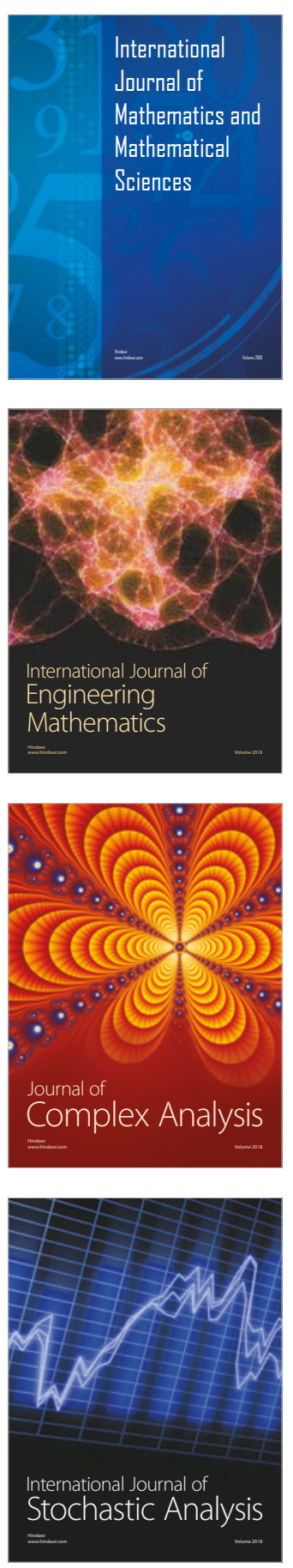
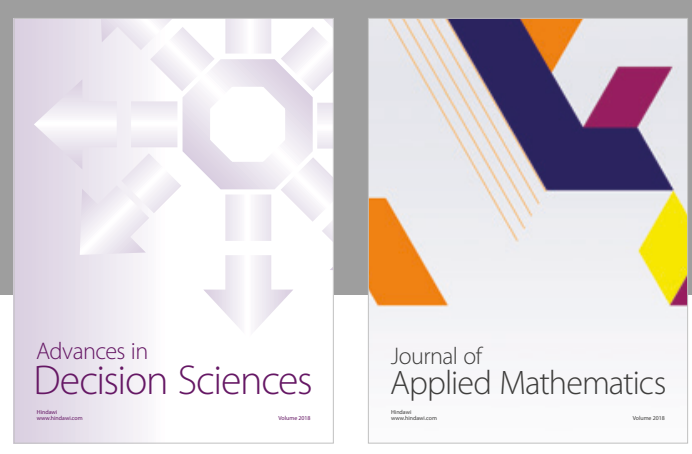

Journal of

Applied Mathematics
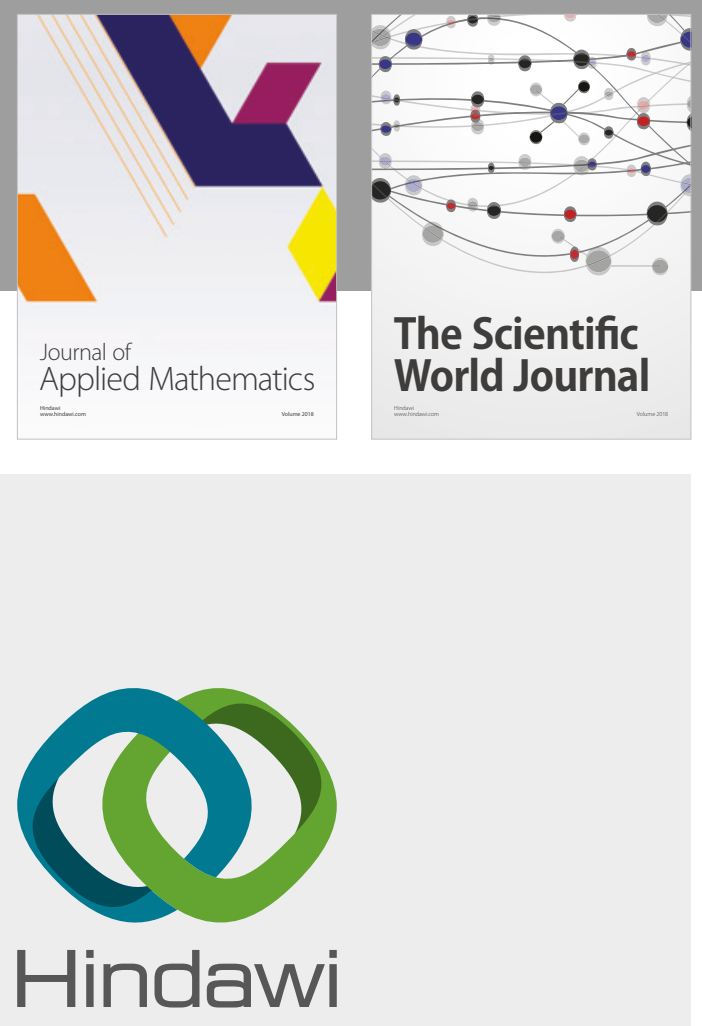

Submit your manuscripts at

www.hindawi.com

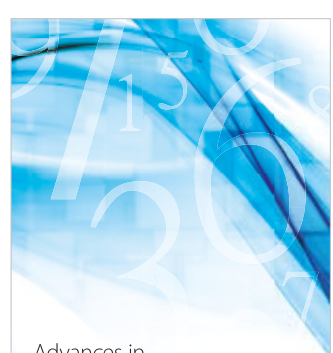

Advances in
Numerical Analysis
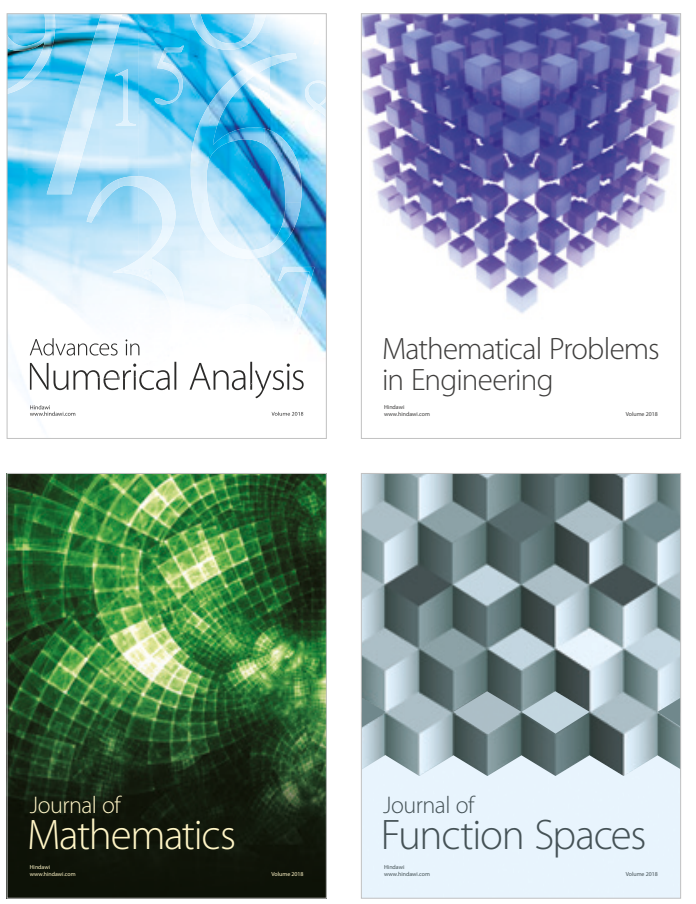

Mathematical Problems in Engineering

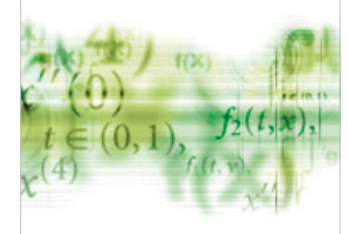

International Journal of

Differential Equations

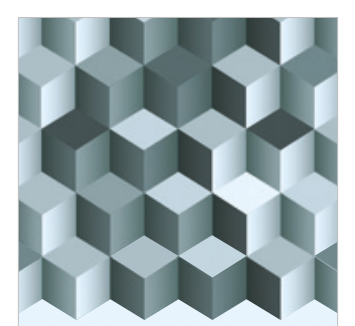

Journal of

Function Spaces

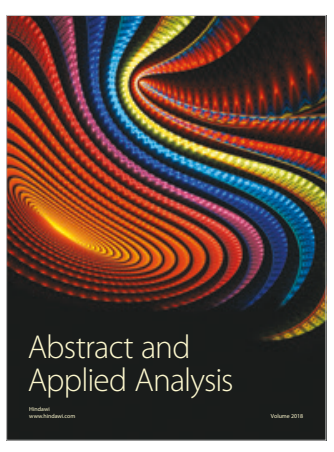

The Scientific

World Journal

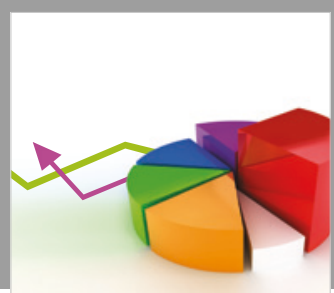

Journal of

Probability and Statistics
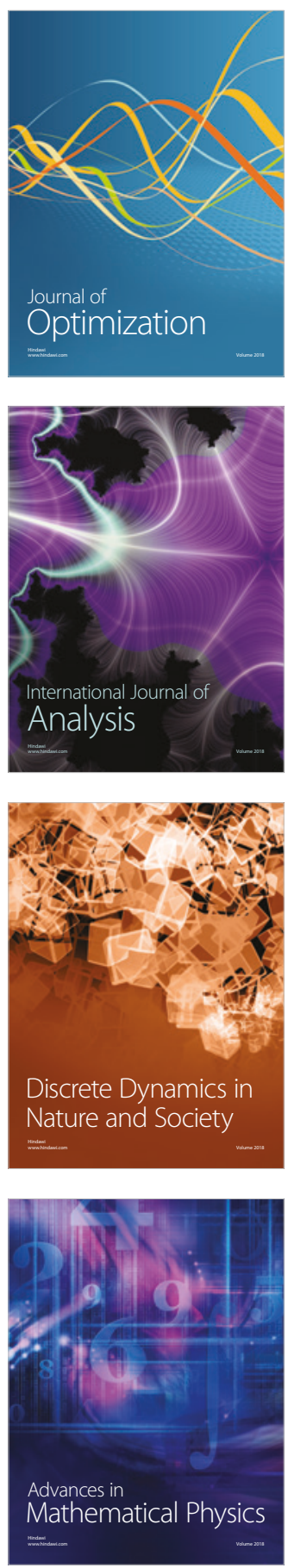